\title{
Changes in left ventricular and atrial mechanics and function after dialysis in patients with end-stage renal disease
}

\author{
Xiaoyan Wang", Jian Hong", Tao Zhang, Di Xu \\ Department of Geriatrics, The First Affiliated Hospital of Nanjing Medical University, Nanjing, China \\ \#These authors contributed equally to this work.
}

Correspondence to: Di Xu. Department of Geriatrics, The First Affiliated Hospital of Nanjing Medical University, 300 Guangzhou Road, Nanjing 210029, China. Email: xudi@jsph.org.cn.

Background: Hemodialysis (HD) can influence end-stage renal disease (ESRD) patients' circulatory system. The present study aimed to evaluate the effect of volume depletion on left ventricular (LV) and left atrial (LA) function and determine the volume-independent parameters before and after HD in patients with ESRD.

Methods: Between January 2018 and January 2019, we recruited long-term HD patients ( $\mathrm{n}=40,51.0 \pm 16.4$ years), excluding those with structural cardiac disease. Echocardiographic parameters, including LV and LA volumes, flow Doppler, pulsed tissue Doppler, and speckle tracking echocardiography (STE) before and after HD (within $24 \mathrm{~h}$ ), were examined, and the values were compared.

Results: Following HD, alteration in LV end-systolic volume was not detected, whereas LV end-diastolic volume $(90.18 \pm 23.91$ vs. $84.21 \pm 23.54 \mathrm{~mL}, \mathrm{P}=0.036)$ and $\mathrm{LV}$ ejection fraction (LVEF; $64.63 \% \pm 6.56 \%$ vs. $62.84 \% \pm 6.56 \%, P=0.049$ ) decreased. Peak early diastolic trans-mitral flow velocity (E-wave; $82.22 \pm 20.13 v s$. $72.43 \pm 18.32 \mathrm{~cm} / \mathrm{s}, \mathrm{P}<0.001$ ), peak early diastolic tissue Doppler velocity (e'; $6.45 \pm 1.88$ vs. $5.77 \pm 1.63 \mathrm{~cm} / \mathrm{s}$, $\mathrm{P}<0.001)$ at the septal side of the mitral annulus, the ratio of early to late Doppler velocities of diastolic mitral inflow $(0.90 \pm 0.27$ vs. $0.79 \pm 0.23, \mathrm{P}<0.001)$, and the average $\mathrm{E} / \mathrm{e}$ ' ratio $(12.54 \pm 4.08$ vs. $11.28 \pm 4.52, \mathrm{P}=0.049)$ decreased significantly. No significant difference was found in peak blood flow velocity at the mitral valve during late diastole and $\mathrm{e}^{\prime}$ at the lateral side of the mitral annulus after HD. LA volume index $(35.55 \pm 12.61$ vs. $\left.30.22 \pm 9.80 \mathrm{~mL} / \mathrm{m}^{2}, \mathrm{P}<0.001\right)$, tricuspid regurgitation velocity $(260.11 \pm 36.54$ vs. $242.37 \pm 32.22 \mathrm{~cm} / \mathrm{s}$, $\mathrm{P}=0.002)$, and pulmonary artery systolic pressure $(33.63 \pm 11.29$ vs. $29.94 \pm 7.80 \mathrm{mmHg}, \mathrm{P}=0.006)$ significantly decreased. LV global longitudinal systolic strain (GLS) of 4-chamber view $(-24.37 \% \pm 3.02 \%$ vs. $-23.38 \% \pm 3.33 \%, \mathrm{P}=0.019)$, rather than global circumferential systolic strain, exhibited significant change after HD. Significant changes were also found in LV longitudinal early diastolic strain rate (LSRe; $1.17 \pm 0.25$ vs. $\left.1.05 \pm 0.24 \mathrm{~s}^{-1}, \mathrm{P}<0.001\right)$ and early diastolic global radial velocity $(\mathrm{Ve} ; 2.62 \pm 0.59$ vs. $2.25 \pm 0.67 \mathrm{~cm} / \mathrm{s}$, $\mathrm{P}=0.011$ ) after $\mathrm{HD}$, but not in other strain rates and global radial velocity measurements. LA maximal volume $\left(35.55 \pm 12.61\right.$ vs. $\left.30.22 \pm 9.80 \mathrm{~mL} / \mathrm{m}^{2}, \mathrm{P}<0.001\right)$, LA total emptying fraction $(54.19 \% \pm 10.39 \%$ vs. $49.63 \% \pm 11.05 \%, \mathrm{P}=0.009)$, and LA passive emptying fraction $(32.23 \% \pm 12.86 \%$ vs. $26.81 \% \pm 9.28 \%, \mathrm{P}=0.004)$ decreased significantly after HD, while LA minimal volume, the volume at the onset of atrial systole, and LA active emptying fraction after HD were not significantly different.

Conclusions: Most indices of systolic (LVEF and GLS of 4-chamber view) and early diastolic function (E-wave, e', LSRe, global radial Ve, and LA passive emptying fraction) were preload dependent. Late diastolic indices, including LV late diastolic global longitudinal strain rate, late diastolic global radial velocity, and LA active emptying fraction, did not change with volume depletion.

Keywords: End-stage renal disease (ESRD); hemodialysis (HD); echocardiography; systolic function; diastolic function

Submitted Aug 10, 2020. Accepted for publication Dec 01, 2020.

doi: 10.21037/qims-20-961

View this article at: http://dx.doi.org/10.21037/qims-20-961 


\section{Introduction}

Patients with end-stage renal disease (ESRD) undergoing hemodialysis (HD) tend to have changes in cardiac structure and function, which have been recognized as key prognostic factors $(1,2)$. A myriad of mechanisms, such as chronic volume and pressure overload, anemia, uremia, high-flow arteriovenous shunts, fluid retention, abnormal calcium and phosphate metabolism, and hyperparathyroidism, can lead to cardiac abnormalities $(3,4)$. Also, HD-induced acute hemodynamic changes in electrolytes, arterial pressure, blood volume, and sympathovagal balance can negatively impact cardiac function (5). Diastolic dysfunction is prevalent among patients with renal insufficiency, but estimating the degree of impaired left ventricular (LV) filling depends on the loading conditions (6). During standard HD, the volume of blood vessels changes significantly, which significantly influences the echocardiographic assessment of diastolic dysfunction.

Speckle tracking echocardiography (STE) can assess LV myocardial deformation in the longitudinal (7), circumferential (8), and radial directions in a simple and angle-independent manner to detect subclinical uremic cardiomyopathy. $\mathrm{LV}$ strain has been proposed to be a new indicator of systolic function.

However, using STE to assess HD's acute impacts on cardiac function has created contradictory results (9-13). To the best of our knowledge, the present study is the first to evaluate the effect of volume depletion on LV and left atrial (LA) physiology together. In the present study, the effects of HD-induced preload reduction on LV and LA function were determined in patients undergoing long-term HD by echocardiography, including pulsed Doppler, tissue Doppler, and 2D STE.

\section{Methods}

\section{Patients}

The present study was designed as a prospective cohort on 40 patients followed in the Nephrology Department's HD unit, The First Affiliated Hospital of Nanjing Medical University, Nanjing, China, between January 2018 and January 2019. Patients between 18-85 years of age with sinus rhythm, who underwent HD 2-3 times a week for at least 1 month and could provide written informed consent were recruited in the study. The exclusion criteria were acute myocardial ischemia, systolic heart failure, structural heart disease, pulmonary embolism, active infection, pericardial disease, and atrial fibrillation.

Patients underwent echocardiography immediately before and within $24 \mathrm{~h}$ after routine HD. Echocardiographic studies were performed by an experienced operator. LV and LA volumes, flow Doppler, pulsed tissue Doppler, and STE were used to evaluate the cardiac function. All echocardiographic measurements were averaged over 3 cardiac cycles during quiet respiration, and cardiac cycle loops with triggered electrocardiogram were stored for offline analysis.

\section{Conventional echocardiography}

The Philips iE33 ultrasound instrument with a S5-1 probe was used together with a Q-Lab digital workstation (Philips Medical Systems, Bothell, WA, USA) for offline analysis. Echocardiography was performed before the start of dialysis and within $24 \mathrm{~h}$ of the end of HD. LV ejection fraction (LVEF) was assessed using the biplane Simpson's method from apical 4- and 2-chamber views (14). Peak early (E) and late (A) diastolic velocities of the mitral inflow and the early diastolic peak velocities (e') of the septal and lateral mitral annulus were evaluated by pulse wave Doppler and tissue Doppler imaging (TDI). LV diastolic function was then estimated by E/A and E/e' ratios (15). Tricuspid regurgitation velocity (TRV) and right atrium pressure were employed to estimate pulmonary artery systolic pressure (PASP). Color M-mode Doppler flow propagation velocity (Vp) was calculated by mitral inflow during diastole combining colorflow Doppler and M-mode. LA volume index (LAVi) was measured using the biplane area length method and was indexed to body surface area. The acquisition of 2D standard views and Doppler images was made according to American Society of Echocardiography (ASE) recommendations (14).

\section{D STE}

2D grayscale images were recorded using a frame rate of $>50$ frames/s from the apical 4-, 2-, 3-chamber views, and the parasternal short-axis views at the basal, papillary muscle, and apical levels. At least 3 consecutive cardiac cycles were recorded. Offline analyses were performed using Automated Cardiac Motion Quantification software on Q-lab version 10.4. For LV apical planes, the region of interest (ROI) was assessed by identifying 3 points, 2 points on both sides of the mitral valve annulus, and 1 point at the apex. Next, myocardial motion in the ROI was retrieved on each frame, in which manual adjustment was applied when necessary (Figure 1). Using the software, global longitudinal 


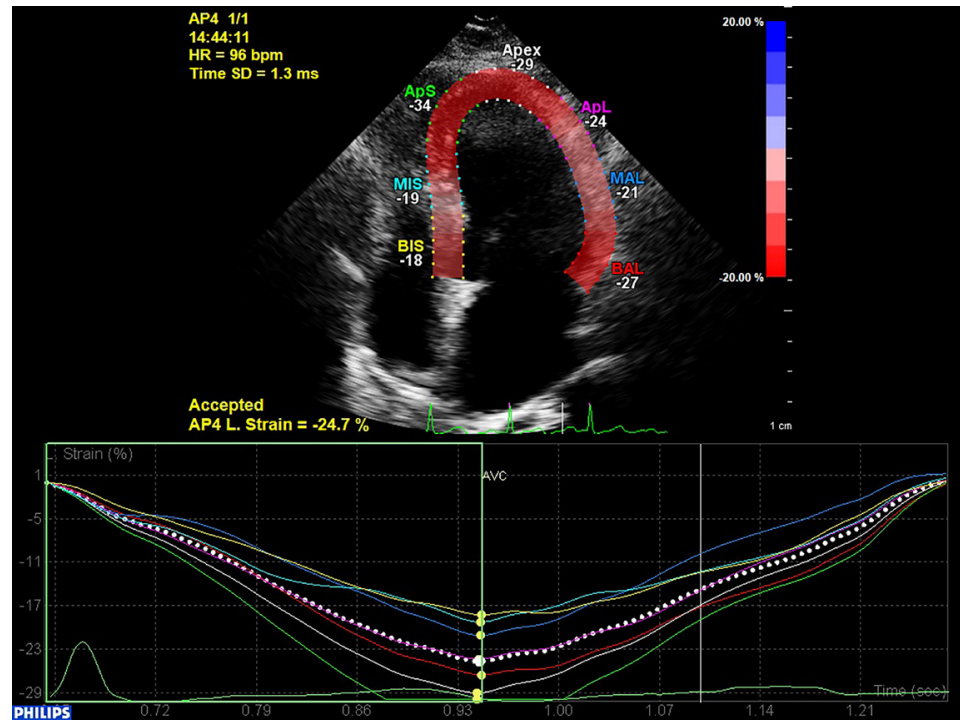

Figure $12 \mathrm{D}$ speckle-tracking echocardiography for left ventricular 4-chamber longitudinal strain.

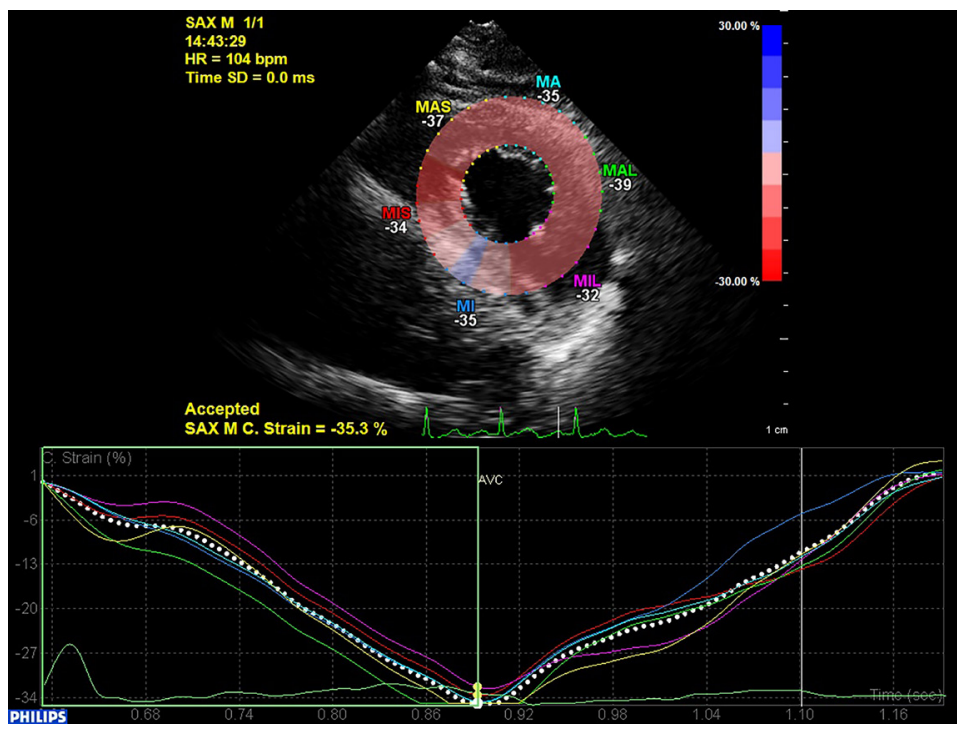

Figure 2 2D speckle-tracking echocardiography for short-axis papillary muscle level circumferential strain.

systolic strain (GLS), GLS strain rate, LV longitudinal early diastolic strain rate (LSRe), and LV late diastolic global longitudinal strain rate (LSRa) were automatically generated. After placing the circle on the image area for $\mathrm{LV}$ short-axis planes, the ROI was traced using the software. The manual adjustment was also made in the desired regions when necessary to optimize tracking. Finally, global circumferential strain (GCS), circumferential systolic strain rate, early diastolic strain rate, late diastolic strain rate, global radial systolic velocity, early diastolic velocity (Ve), and late diastolic velocity were generated (Figure 2).

\section{LA function}

To evaluate LA function, 3 different phasic LA volumes were obtained; the maximum volume of the LA (LAVmax) was obtained just before the opening of the mitral valve, the minimum volume of the LA (LAVmin) was obtained at the closure of the mitral valve and the LA volume at the onset of P-wave on the electrocardiogram (LAVpreA). LA 
function, including LA reservoir, conduit, and booster pump function, was calculated as previously described using the following formulae: LA total (reservoir) emptying fraction $($ LAEFtotal $)=($ LAVmax $-\mathrm{LAVmin}) / \mathrm{LAVmax} ; \mathrm{LA}$ passive (conduit) emptying fraction (LAEFpassive $)=(\mathrm{LAVmax}-$ LAVpreA)/LAVmax; LA active (pump) emptying fraction $($ LAEFactive $)=($ LAVpreA-LAVmin $) /$ LAVpreA $)(16,17)$.

\section{Statistical analysis}

Continuous variables were presented as means \pm

Table 1 Baseline characteristics and medications of study cohort $(\mathrm{n}=40)$

\begin{tabular}{lc}
\hline Clinical characteristics & Value \\
\hline Age (years) & $51.0 \pm 16.4$ \\
Sex (male\%) & $67.5 \%$ \\
Duration of dialysis (years) & $4.31 \pm 4.18$ \\
Current or ex-smoker (\%) & $10 \%$ \\
Body surface area ( ${ }^{2}$ ) & $1.68 \pm 0.22$ \\
Cause of renal failure (\%) & \\
Diabetes mellitus & 7.5 \\
Hypertension & 10 \\
Chronic glomerulonephritis & 40 \\
Polycystic kidney disease & 10 \\
Others causes or cryptogenic & 32.5 \\
Current medication (\%) & \\
ACEl/ARB & 18.3 \\
B-blocker & 21.7 \\
Calcium channel blocker & 40 \\
Statin & 1.7 \\
\hline
\end{tabular}

ACEI/ARB, angiotensin converting enzyme inhibitor/angiotensin receptor blocker. standard deviations and categorical data as percentages or frequencies. All statistical analyses were conducted using SPSS version 22.0 software (IBM, Armonk, NY, USA). Comparisons were made using paired samples $t$-test or Wilcoxon test. $\mathrm{P}<0.05$ was considered statistically significant.

\section{Results}

The baseline characteristics of participants are presented in Table 1. We included 40 patients with ESRD (27 males and 13 females, aged $51.0 \pm 16.4$ years) and treated by HD for $4.31 \pm 4.18$ years. The most common causes of ESRD were as follows: chronic glomerulonephritis (40\%), polycystic kidney disease $(10 \%)$, arterial hypertension (10\%), and diabetes mellitus $(7.5 \%)$. There was a decrease in both systolic and diastolic blood pressures after HD, as shown in Table 2. However, no significant changes were detected in heart rate after HD.

\section{Echocardiography of LV function}

The changes in the echo parameters of LV geometry and systolic function before and after HD are shown in Table 3 . Following HD, LV end-systolic volume did not change, but $\mathrm{LV}$ end-diastolic volume $(90.18 \pm 23.91$ vs. $84.21 \pm 23.54 \mathrm{~mL}$, $\mathrm{P}=0.036)$ and LVEF $(64.63 \% \pm 6.56 \%$ vs. $62.84 \% \pm 6.56 \%$, $\mathrm{P}=0.049)$ decreased. Pulsed Doppler echocardiography showed significantly decreased $\mathrm{E}$-wave peak velocity $(82.22 \pm 20.13$ vs. $72.43 \pm 18.32 \mathrm{~cm} / \mathrm{s}, \mathrm{P}<0.001)$ and $\mathrm{E} / \mathrm{A}$ ratio $(0.90 \pm 0.27$ vs. $0.79 \pm 0.23, \mathrm{P}<0.001)$ for mitral valves. Spectral Doppler revealed a significant decrease of e' at the septal side of the mitral annulus $(6.45 \pm 1.88 v s .5 .77 \pm 1.63 \mathrm{~cm} / \mathrm{s}$, $\mathrm{P}<0.001)$, and the average value of the septal and lateral side $(7.10 \pm 2.14$ vs. $6.53 \pm 1.98 \mathrm{~cm} / \mathrm{s}, \mathrm{P}=0.003)$, while the lateral side value showed no difference before and after HD. In addition, the average E/e' ratio decreased significantly $(12.54 \pm 4.08$ vs. $11.28 \pm 4.52, \mathrm{P}=0.049)$, and

Table 2 Clinical parameters before and after HD

\begin{tabular}{lccc}
\hline Parameters & Pre-HD & Post-HD & P value \\
\hline SBP $(\mathrm{mmHg})$ & $139.40 \pm 14.81$ & $126.09 \pm 23.95$ & $0.002^{\star \star}$ \\
DBP $(\mathrm{mmHg})$ & $82.60 \pm 10.62$ & $77.03 \pm 9.53$ & $0.002^{\star \star}$ \\
Heart rate (beats/min) & $74.88 \pm 9.74$ & $74.60 \pm 9.37$ & 0.839 \\
Weight $(\mathrm{kg})$ & $64.56 \pm 14.18$ & $61.92 \pm 14.05$ & $<0.001^{\star \star *}$ \\
\hline
\end{tabular}

${ }^{\star \star} \mathrm{P}<0.01,{ }^{\star \star \star} \mathrm{P}<0.001$ vs. Pre-HD. DBP, diastolic blood pressure; HD, hemodialysis; SBP, systolic blood pressure. 
Table 3 Conventional echocardiography and pulsed Doppler parameters before and after HD

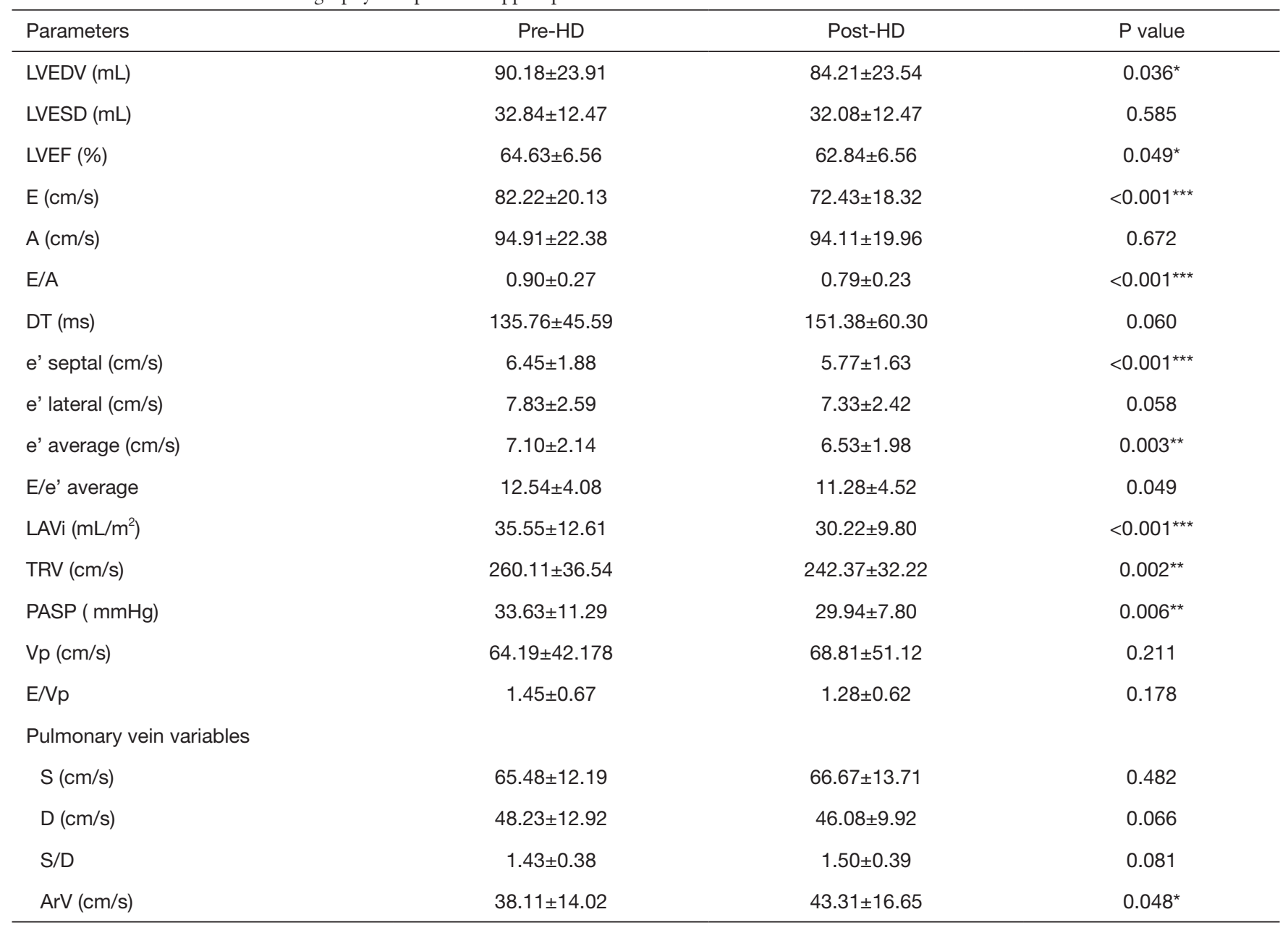

${ }^{\star} \mathrm{P}<0.05,{ }^{\star \star} \mathrm{P}<0.01,{ }^{* \star *} \mathrm{P}<0.001$ vs. Pre-HD. A, peak late diastolic trans-mitral flow velocity; ArV, velocity of atrial reversal; $\mathrm{D}$, pulmonary vein flow peak velocity during diastole; DT, deceleration time of the E-wave; E, peak early diastolic trans-mitral flow velocity; e' lateral, early diastolic velocity at the lateral mitral annulus; e' septal, early diastolic velocity at the septal mitral annulus; HD, hemodialysis; LAVi, left atrial volume indexed to body surface area; LVEDV, left ventricle end-diastolic volume; LVEF, left ventricle ejection fraction; LVESV, left ventricle end-diastolic volume; PASP, pulmonary artery systolic pressure; S, pulmonary vein flow peak velocity during systole.

LAVi $\left(35.55 \pm 12.61\right.$ vs. $\left.30.22 \pm 9.80 \mathrm{~mL} / \mathrm{m}^{2}, \mathrm{P}<0.001\right)$, TRV $(260.11 \pm 36.54$ vs. $242.37 \pm 32.22 \mathrm{~cm} / \mathrm{s}, \mathrm{P}=0.002)$, and PASP $(33.63 \pm 11.29$ vs. $29.94 \pm 7.80 \mathrm{mmHg}, \mathrm{P}=0.006)$ also decreased significantly. No significant differences were observed for pulmonary vein variables except atrial reversal velocity $(38.11 \pm 14.02$ vs. $43.31 \pm 16.65 \mathrm{~cm} / \mathrm{s}, \mathrm{P}=0.048)$.

\section{Strain and strain rate measurements}

LV GLS of 4-chamber view decreased significantly after HD $(-24.37 \% \pm 3.02 \%$ vs. $-23.38 \% \pm 3.33 \%, \mathrm{P}=0.019)$. In contrast, no notable alteration was detected for GCS between pre- and post-HD (Table 4). Significant differences were found in LV LSRe $\left(1.17 \pm 0.25\right.$ vs. $1.05 \pm 0.24 \mathrm{~s}^{-1}$, $\mathrm{P}<0.001)$, and global radial Ve $(2.62 \pm 0.59$ vs. $2.25 \pm 0.67 \mathrm{~cm} / \mathrm{s}$, $\mathrm{P}=0.011)$. Changes for other strain rates and global radial velocity measurements were not significantly different.

\section{LA function}

LAVmax $\left(35.55 \pm 12.61\right.$ vs. $\left.30.22 \pm 9.80 \mathrm{~mL} / \mathrm{m}^{2}, \mathrm{P}<0.001\right)$, LAEFtotal $(54.19 \% \pm 10.39 \%$ vs. $49.63 \% \pm 11.05 \%, \mathrm{P}=0.009)$, and LAEFpassive $(32.23 \% \pm 12.86 \%$ vs. $26.81 \% \pm 9.28 \%$, $\mathrm{P}=0.004)$ decreased significantly after $\mathrm{HD}$, while no significant difference was found in LAVpreA, LAVmin and LAEFactive before and after HD (Table 5). 
Table 4 2D speckle tracking strain measurements of left ventricle before and after hemodialysis

\begin{tabular}{|c|c|c|c|}
\hline Parameters & Before HD & After HD & $P$ value \\
\hline GCS (\%) & $-30.32 \pm 6.50$ & $-30.23 \pm 6.25$ & 0.931 \\
\hline $\operatorname{LSRs}\left(s^{-1}\right)$ & $-1.13 \pm 0.16$ & $-1.18 \pm 0.19$ & 0.063 \\
\hline $\operatorname{LSRe}\left(\mathrm{s}^{-1}\right)$ & $1.17 \pm 0.25$ & $1.05 \pm 0.24$ & $<0.001^{\star \star *}$ \\
\hline $\operatorname{CSRs}\left(\mathrm{s}^{-1}\right)$ & $-1.81 \pm 0.28$ & $-1.85 \pm 0.46$ & 0.642 \\
\hline $\operatorname{CSRe}\left(\mathrm{s}^{-1}\right)$ & $1.98 \pm 0.42$ & $1.88 \pm 0.53$ & 0.334 \\
\hline $\operatorname{CSRa}\left(\mathrm{s}^{-1}\right)$ & $1.53 \pm 0.46$ & $1.61 \pm 0.45$ & 0.381 \\
\hline Global radial Vs $(\mathrm{cm} / \mathrm{s})$ & $2.56 \pm 0.40$ & $2.46 \pm 0.60$ & 0.366 \\
\hline
\end{tabular}

${ }^{*} \mathrm{P}<0.05$, ${ }^{* \star} \mathrm{P}<0.001$ vs. Pre-HD. HD, hemodialysis; CSRa, global circumferential late diastolic strain rate; CSRe, global circumferential early diastolic strain rate; CSRs, global circumferential systolic strain rate; GCS, global circumferential systolic strain; GLS, global longitudinal systolic strain; LSRa, global longitudinal late diastolic strain rate; LSRe, global longitudinal early diastolic strain rate; LSRs, global longitudinal systolic strain rate; Va, late diastolic velocity; Ve, early diastolic velocity; Vs, systolic velocity.

Table 5 Changes in parameters of left atrium geometry and function before and after HD

\begin{tabular}{lccc}
\hline Parameters & Pre-HD & Post-HD & P value \\
\hline LAVmax $\left(\mathrm{mL} / \mathrm{m}^{2}\right)$ & $35.55 \pm 12.61$ & $30.22 \pm 9.80$ & $<.001^{\star \star \star}$ \\
LAVpreA $\left(\mathrm{mL} / \mathrm{m}^{2}\right)$ & $24.35 \pm 10.77$ & $22.25 \pm 8.22$ & 0.057 \\
LAVmin $\left(\mathrm{mL} / \mathrm{m}^{2}\right)$ & $16.46 \pm 8.20$ & $15.44 \pm 7.13$ & 0.237 \\
LAEFtotal $(\%)$ & $54.19 \pm 10.39$ & $49.63 \pm 11.05$ & $0.009^{\star \star}$ \\
LAEFpassive (\%) & $32.23 \pm 12.86$ & $26.81 \pm 9.28$ & $0.004^{\star \star}$ \\
LAEFactive (\%) & $31.80 \pm 11.35$ & $31.21 \pm 12.03$ & 0.785 \\
\hline
\end{tabular}

${ }^{* *} \mathrm{P}<0.01,{ }^{* *} \mathrm{P}<0.001$ vs. Pre-HD. HD, hemodialysis; LAEFactive, left atrium active emptying fraction; LAEFpassive, left atrium passive emptying fraction; LAEFtotal, left atrium total emptying fraction; LAVmax, left atrium maximum volume; LAVmin, left atrium minimum volume; LAVpreA, left atrium volume at the onset of $\mathrm{P}$-wave on the electrocardiogram.

\section{Discussion}

Our main finding was that most systolic and early diastolic function indices were preload dependent, but late diastolic indices were minimally affected by preload. Several studies have investigated preload reduction-induced cardiac function changes but showed contradictory results (18-23). Missant et al. demonstrated that acute lowering of right ventricle preload did not affect either the maximum strain rate or isovolumic strain acceleration (18). Lee et al. reported that no significant change was found for myocardial peak systolic velocity and peak late diastolic velocity; however, there was a significant reduction of myocardial early diastolic phase peak velocity (19). Becker et al. reported a relative decrease of radial strain by $9.4 \% \pm 7.7 \%$ after valve replacement for aortic regurgitation (20). Several studies reported that HD-induced myocardial stunning or regional LV systolic dysfunction occurred in some patients (21-23), which explained our result that LVEF and GLS decreased significantly after HD. 


\section{Impact of HD on LV systolic function}

Our study revealed that LVEF and GLS decreased significantly after HD, which is in line with the findings of several previous studies (11-13). Ünlü and his colleagues found that myocardiac troponin $\mathrm{T}$ increased with the decline of GLS after HD (11). In another study of 3D STE measurements of 58 adults, GLS decreased significantly after dialysis (24). In contrast, Mendes et al. found no changes in GLS after HD (9). Murata et al. also found no significant change in both global longitudinal and circumferential strains of adult patients after dialysis (10). Also, Amoozgar et al. found no changes in GLS in children after dialysis, and believed that children's STE was preload independent (25). In our study, no notable change was observed for global circumferential systolic strain after HD. These results suggest that circumferential systolic strain is not sensitive to preload.

The decrease in afterload can improve LV systolic function. GLS should increase after blood pressure decreases (18). However, in our study, when patients' blood pressure decreased after dialysis, GLS still decreased. This indirectly shows that GLS is preload dependent. According to the Starling curve, the reduction of preload leads to reduced LV function, which may explain the reduced GLS after HD observed in the present study. Burton and colleagues reported that $64 \%$ of patients developed significant $\mathrm{LV}$ regional wall motion abnormalities; during HD, patients with significant regional wall motion abnormalities had a significant drop in LVEF (22). These findings suggest that $\mathrm{HD}$-induced $\mathrm{LV}$ dysfunction occurs in the majority of ESRD patients.

\section{Impact of HD on LV diastolic and LA measurements}

We found that HD-associated volume reduction changed mitral valve inflow parameters, with typical preload reduction. Because E-wave velocity was significantly lower than A-wave velocity after HD, the E/A ratio decreased, which is consistent with previous studies regarding HD's effect on LV filling echocardiographic parameters $(26,27)$. Dincer and colleagues found that the mitral inflow E- and A-wave velocities and E/A ratio reduced significantly after HD (26). Agmon and colleagues showed that the velocity of mitral inflow $\mathrm{E}$ decreased, and deceleration time increased with a smaller decline in mitral inflow A velocity after HD, which resulted in a significant decline in the E/A ratio (27).

TDI e' velocity also decreased on the septal mitral annulus. Mean E/e' was slightly reduced after HD, which was likely to be caused by more decrease in $\mathrm{E}$ velocity than e'. Dincer et al. and Agmon et al. reported significantly decreased TDI-derived velocities of diastolic myocardial function after HD (26,27). Furthermore, Hung et al. demonstrated that the TDI indices of $\mathrm{LV}$ diastolic function altered with loading changes (28).

These findings indicate that the mitral annular velocities are also preload dependent. In our cases, $\mathrm{Vp}$ was a preloadindependent indicator of diastolic function in chronic patients with prevalent isolated diastolic dysfunction.

Although strain was thought to be independent of loading conditions, subsequent studies showed contradictory results $(18,28)$. Obvious changes were seen in early diastolic strain rate measurements of both the right ventricle and right atrium (29).

The most important function of the LA is to regulate the LV filling. LA acts as a reservoir for a pulmonary venous return during ventricular systole, a conduit for a pulmonary venous return during early diastole, and a powerful pump to augment the LV filling during late diastole. During the cardiac cycle, it is important to recognize the interaction between the LV performance and the function of the LA. For example, the LA reservoir function is not only affected by the compliance of the LA, but also related to the systolic function and end-systolic volume of the LV. Conduit function is related to the compliance of the LA and the relaxation and compliance of the LV. Finally, the pump function of LA reflects LA contractility, but is also related to venous return (atrial preload), LV end-diastolic pressure, and LV systolic reserve (30). The present study showed that volume depletion led to significantly changed LV LSRe and radial Ve, LAVmax, and LAEFpassive. However, no significant changes could be induced by volume depletion in the LSRa of the LV, LAVpreA, LAVmin, and LAEFactive. Our results suggested that increased preload mainly affected the reservoir and conduit phases, and therefore a large proportion of blood might be transferred to the LV during the conduit phase (early filling phase), which could lead to reduce blood volume in the LA during the contraction. The LA contraction phase corresponds to the ventricular late diastolic phase, in which the remaining blood after the early filling phase is pumped to the ventricle. It can be assumed that the elevated preload has no direct effect on the LA contractile function. The fact that only early, but not late, the diastolic strain rate is load dependent can be explained by ventricular filling physiology. When a large volume of blood is transferred to the $\mathrm{LV}$, the volume overload may 
impact the early diastolic phase of the $\mathrm{LV}$ and conduit phase of LA. Therefore, the rest volume of LA in the contraction phase is not directly related to body volume status. Our findings support this hypothesis because no significant changes were found in LAVpreA and LAVmin before and after HD.

The acute changes in echo parameters after HD might be related to serum ionized calcium concentration changes, sympathetic hyperactivity, increased oxidative stress during $\mathrm{HD}$, and low-resistant vessels (31).

The current guideline does not recommend the optimal timing of echocardiographic evaluation in patients with ESRD, and volume overload before HD will underestimate diastolic dysfunction. Therefore, LV diastolic function should be evaluated in a relatively euvolemic state.

\section{Study limitations}

This study was a single-center, small-sample preliminary study, and its conclusions need to be further confirmed by a more rigorous and large-sample prospective study. Another limitation was the impossibility of blinding the study because the echocardiographer who acquired the images knew the dialysis time.

\section{Conclusions}

Echocardiographic evaluation of the systolic and diastolic function of ESRD patients undergoing HD depends on the time of dialysis. Our findings suggest that the evaluation of cardiac function should be performed at the end of dialysis, and that limiting inter-dialytic weight gain and keeping a low ultrafiltration volume may help preserve the patients' cardiac function.

\section{Acknowledgments}

We thank the authors of the primary studies for their timely and helpful responses to our information requests.

Funding: The present study was supported by the National Natural Science Foundation of China (Grant No. 81871359) and by the Natural Science Foundation of Jiangsu Province (No. BK20191496).

\section{Footnote}

Conflicts of Interest: All authors have completed the ICMJE uniform disclosure form (available at http://dx.doi. org/10.21037/qims-20-961). The authors have no conflicts of interest to declare.

Etbical Statement: The study protocol was approved by the Institutional Review Board of Jiangsu Province Hospital. Written informed consent was obtained from the patients for publication of this study and any accompanying images. A copy of the written consent is available for review by the Editor-in-Chief of this journal.

Open Access Statement: This is an Open Access article distributed in accordance with the Creative Commons Attribution-NonCommercial-NoDerivs 4.0 International License (CC BY-NC-ND 4.0), which permits the noncommercial replication and distribution of the article with the strict proviso that no changes or edits are made and the original work is properly cited (including links to both the formal publication through the relevant DOI and the license). See: https://creativecommons.org/licenses/by-nc-nd/4.0/.

\section{References}

1. Foley RN, Parfrey PS, Sarnak MJ. Clinical epidemiology of cardiovascular disease in chronic renal disease. Am J Kidney Dis 1998;32:S112-9.

2. Locatelli F, Del VL, Manzoni C. Morbidity and mortality on maintenance haemodialysis. Nephron 1998;80:380-400.

3. Schärer K, Schmidt KG, Soergel M. Cardiac function and structure in patients with chronic renal failure. Pediatr Nephrol 1999;13:951-65.

4. London G. Pathophysiology of cardiovascular damage in the early renal population. Nephrol Dial Transplant 2001;16 Suppl 2:3-6.

5. Karayaylali I, San M, Kudaiberdieva G, NiyazovaKarben Z, Seyrek N, Balal M, Paydas S, Sagliker Y. Heart rate variability, left ventricular functions, and cardiac autonomic neuropathy in patients undergoing chronic hemodialysis. Ren Fail 2003;25:845-53.

6. Nagueh SF, Smiseth OA, Appleton CP, Byrd BR, Dokainish H, Edvardsen T, Flachskampf FA, Gillebert TC, Klein AL, Lancellotti P, Marino P, Oh JK, Popescu $\mathrm{BA}$, Waggoner AD. Recommendations for the evaluation of left ventricular diastolic function by echocardiography: An update from the american society of echocardiography and the european association of cardiovascular imaging. J Am Soc Echocardiogr 2016;29:277-314.

7. D'Ascenzi F, Caselli S, Solari M, Pelliccia A, Cameli M, Focardi M, Padeletti M, Corrado D, Bonifazi M, 
Mondillo S. Novel echocardiographic techniques for the evaluation of athletes' heart: A focus on speckle-tracking echocardiography. Eur J Prev Cardiol 2016;23:437-46.

8. Chu M, Qian L, Zhu M, Yao J, Xu D, Chen M. Circumferential strain rate to detect lipopolysaccharideinduced cardiac dysfunction: A speckle tracking echocardiography study. Quant Imaging Med Surg 2019;9:151-9.

9. Mendes L, Ribeiras R, Adragao T, Lima S, Horta E, Reis C, Amaral T, Aguiar C, Gouveia R, Silva A. Loadindependent parameters of diastolic and systolic function by speckle tracking and tissue doppler in hemodialysis patients. Rev Port Cardiol 2008;27:1011-25.

10. Murata T, Dohi K, Onishi K, Sugiura E, Fujimoto $\mathrm{N}$, Ichikawa K, Ishikawa E, Nakamura M, Nomura S, Takeuchi H, Nobori T, Ito M. Role of haemodialytic therapy on left ventricular mechanical dyssynchrony in patients with end-stage renal disease quantified by speckle-tracking strain imaging. Nephrol Dial Transplant 2011;26:1655-61.

11. Ünlü S, Sahinarslan A, Sezenoz B, Uludag OM, Gokalp G, Seckin O, Arinsoy ST, Gulbahar O, Boyaci NB. High-sensitive troponin $\mathrm{T}$ increase after hemodialysis is associated with left ventricular global longitudinal strain and ultrafiltration rate. Cardiol J 2020;27:376-83.

12. Choi JO, Shin DH, Cho SW, Song YB, Kim JH, Kim YG, Lee SC, Park SW. Effect of preload on left ventricular longitudinal strain by $2 \mathrm{D}$ speckle tracking. Echocardiography 2008;25:873-9.

13. Ibrahim SS, Koura M, Emara A, Kamel M. The effect of hemodialysis-induced preload changes on the left ventricular function: A speckle-tracking echocardiographic study. Menoufia Med J 2016;29:406-11.

14. Lang RM, Badano LP, Mor-Avi V, Afilalo J, Armstrong A, Ernande L, Flachskampf FA, Foster E, Goldstein SA, Kuznetsova T, Lancellotti P, Muraru D, Picard MH, Rietzschel ER, Rudski L, Spencer K T, T sang W, Voigt JU. Recommendations for cardiac chamber quantification by echocardiography in adults: An update from the American Society of Echocardiography and the European Association of Cardiovascular Imaging. J Am Soc Echocardiogr 2015;28:1-39.e14.

15. Yilmaz R, Baykan M, Erdol C. Pulsed wave tissue Doppler echocardiography. Anadolu Kardiyol Derg 2003;3:54-9.

16. Blume GG, Mcleod CJ, Barnes ME, Seward JB, Pellikka PA, Bastiansen PM, Tsang TS. Left atrial function: Physiology, assessment, and clinical implications. Eur J Echocardiogr 2011;12:421-30.
17. Zhang Y, Sun H, Li M, Luo M, Xu F, Shao Y, Xu D. Impact of stand-alone minimally invasive radiofrequency ablation with left atrial appendectomy on left atrial function assessed by echocardiography. Quant Imaging Med Surg 2020;10:970-8.

18. Missant C, Rex S, Claus P, Mertens L, Wouters PF. Loadsensitivity of regional tissue deformation in the right ventricle: Isovolumic versus ejection-phase indices of contractility. Heart 2008;94:e15.

19. Lee TY, Kang PL, Hsiao SH, Lin SK, Mar GY, Chiou CW, Liu CP. Tissue Doppler velocity is not totally preload-independent: A study in a uremic population after hemodialysis. Cardiology 2007;107:415-21.

20. Becker M, Kramann R, Dohmen G, Luckhoff A, Autschbach R, Kelm M, Hoffmann R. Impact of left ventricular loading conditions on myocardial deformation parameters: Analysis of early and late changes of myocardial deformation parameters after aortic valve replacement. J Am Soc Echocardiogr 2007;20:681-9.

21. Assa S, Hummel YM, Voors AA, Kuipers J, Westerhuis R, de Jong PE, Franssen CF. Hemodialysis-induced regional left ventricular systolic dysfunction: Prevalence, patient and dialysis treatment-related factors, and prognostic significance. Clin J Am Soc Nephrol 2012;7:1615-23.

22. Burton JO, Jefferies HJ, Selby NM, McIntyre CW. Hemodialysis-induced cardiac injury: Determinants and associated outcomes. Clin J Am Soc Nephrol 2009;4:914-20.

23. Hothi DK, Rees L, Marek J, Burton J, McIntyre CW. Pediatric myocardial stunning underscores the cardiac toxicity of conventional hemodialysis treatments. Clin J Am Soc Nephrol 2009;4:790-7.

24. Ahn HS, Kim YK, Song HC, Choi EJ, Kim GH, Cho JS, Ihm SH, Kim HY, Park CS, Youn HJ. The impact of preload on 3-dimensional deformation parameters: Principal strain, twist and torsion. Cardiovasc Ultrasound 2017;15:22.

25. Amoozgar H, Naghshzan A, Basiratnia M, Ahmadipoor M. Effect of hemodialysis on global and regional cardiac function in children with end-stage renal disease. Iran J Kidney Dis 2018;12:48-52.

26. Dincer I, Kumbasar D, Nergisoglu G, Atmaca Y, Kutlay S, Akyurek O, Sayin T, Erol C, Oral D. Assessment of left ventricular diastolic function with Doppler tissue imaging: Effects of preload and place of measurements. Int J Cardiovasc Imaging 2002;18:155-60.

27. Agmon Y, Oh JK, McCarthy JT, Khandheria BK, Bailey KR, Seward JB. Effect of volume reduction on mitral annular diastolic velocities in hemodialysis patients. Am J 
Cardiol 2000;85:665-8, A11.

28. Hung KC, Huang HL, Chu CM, Chen CC, Hsieh IC, Chang ST, Fang JT, Wen MS. Evaluating preload dependence of a novel Doppler application in assessment of left ventricular diastolic function during hemodialysis. Am J Kidney Dis 2004;43:1040-6.

29. Ünlü S, Sahinarslan A, Gokalp G, Seckin O, Arinsoy ST, Boyaci NB, Cengel A. The impact of volume overload on right heart function in end-stage renal disease patients on

Cite this article as: Wang $\mathrm{X}$, Hong $\mathrm{J}$, Zhang T, Xu D. Changes in left ventricular and atrial mechanics and function after dialysis in patients with end-stage renal disease. Quant Imaging Med Surg 2021;11(5):1899-1908. doi: 10.21037/qims20-961 hemodialysis. Echocardiography 2018;35:314-21.

30. Hoit BD. Left atrial size and function: Role in prognosis. J Am Coll Cardiol 2014;63:493-505.

31. Hayashi SY, Brodin LA, Alvestrand A, Lind B, Stenvinkel P, Mazza DNM, Qureshi AR, Saha S, Lindholm B, Seeberger A. Improvement of cardiac function after haemodialysis. Quantitative evaluation by colour tissue velocity imaging. Nephrol Dial Transplant 2004;19:1497-506. 